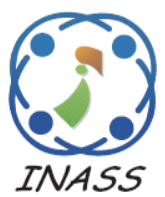

\title{
Circular Split Ring Resonator Loaded Circular Patch Microstrip Antenna for 5.2 GHz ISM Band
}

\author{
Saptarshi Gupta ${ }^{1 *} \quad$ Rattan Lal Sharma $^{1}$ \\ ${ }^{1}$ Department of Electronics \& Communication Engineering, \\ Noida International University, Gautam Budh Nagar, Uttar Pradesh (203201), India \\ * Corresponding author’s Email: ece.saptarshi@gmail.com
}

\begin{abstract}
In this paper, a miniature improved gain Circular Patch Antenna (CPA) is reported. An array of Circular Split Ring Resonators (CSRRs) is loaded into a circular patch to transfigure the surface current distributions leading to miniaturization and significant gain enhancement. To obtain a bi-conical beam, the antenna is operated at Higher Order Mode (HOM). The HOM is excited by suitably selecting the feeding location. The unit cell of the CSRR is analyzed and the permittivity of the CSRRs loaded antenna structure is extracted using Scattering Parameter Inversion (SPI) method. The proposed antenna operates in $5.2 \mathrm{GHz}$ band and built on a thin $(0.254 \mathrm{~mm}) \mathrm{RT} /$ Duroid 5880 substrate thus, flexible in nature. The bending analysis is performed showing a natural frequency shift. To validate the proposed design, the prototype is fabricated showing good agreement amongst simulated and measured results is found.
\end{abstract}

Keywords: Circular patch antenna, Circular split ring resonator, Conformal antenna, Gain enhancement, High-gain antenna, Antenna miniaturization.

\section{Introduction}

Microstrip patch antennas have several advantages such as small in size, less weight, low manufacturing cost, easy fabrication and can be mount on different shape of surface. However, the Microstrip patch antenna suffers with low gain and narrow bandwidth. To combat with these shortcomings several techniques have been suggested such as: Planer multi resonator configuration which provides broad bandwidth but increase the size of the antenna, electromagnetically coupled MSA in which more than one patches are placed on different dielectric layers and they are coupled electromagnetically to the feeding point at the bottom of the dielectric layer but main limitation of this structure is it increases the height of the antenna and which is not suitable for conformal applications, Log periodic MSA configuration used to increase the bandwidth but the radiation pattern varies over the impedance bandwidth also it increases the length of the antenna, Broadband Thick RMSA with Various Probes this technique helps to improve the bandwidth but due to multiple probe use impedance matching is become an issue, Gap-Coupled RMSAs techniques increase the antenna size etc. [1].

Recently Metamaterials are become new trends for fabrication as substrate material used for patch antennas. Metamaterial with negative permeability and permittivity was first hypothetically dissected by Veselago in 1968 [2]. Use of Metamaterials can increase the antenna performance characteristics like antenna gain and bandwidth [3]. Metamaterials are the artificial materials not available in nature having properties like negative permittivity and permeability which natural materials don't have [4]. The metamaterial used as a substrate exhibits large bandwidth and high gain due to the material property [5-7]. In Negative Index Metamaterial (NIM) if both permittivity and permeability are negative then that is called double negative material (DNG) [8]. Ziolkowski and Kipple [9] suggested an 
application of double negative material (DNG) to increase power radiation from small antenna. In addition to this size of the antenna also a very important parameter for several applications like WLAN, military gadgets, personal area communications, advance digital devices etc. demands reduction of antenna size [10]. To achieve the size reduction the complementary split ring resonators (CSRRs) [11-13] are proposed on the ground plane, providing nearly $30 \%$ of size reduction is achieved with FBR (Front to back ratio) close to $1 \mathrm{~dB}$. In [14], a compact monopole CSRR loaded antenna was introduced for dual band (1.9 and $2.5 \mathrm{GHz}$ ) operations. Here more than one layer metasurface used as a ground plane increase the antenna characteristics. For obtaining dual polarized multibeam radiation pattern a holographic multi beamforming antenna was reported in [15]. In [16] an antenna was proposed for wideband satellite communication. This antenna provides circular polarization which is suitable for long distance communication. The frequency of operations is fixed to $5.2 \mathrm{GHz}$. In [17] a small size metasurface lens is used to increase antenna gain in boresight direction which is suitable for directional antenna. In [18] three different designs like nearly square, nearly square corner trimmed and nearly square corner trimmed with slot antenna was proposed for $5.2 \mathrm{GHz}$ wireless applications. Recently, an efficient and effective optimistic technique is utilized for selection of cloud service provider in a smart city by M. Sarkar et al. [19]. For parameter antenna optimization fuzzy techniques may be adopted.

In this paper, we present a circular split ring resonator loaded circular patch Microstrip antenna. This structure operates at $5.2 \mathrm{GHz}$ (ISM-band) [20] and probe feed is used to feed the antenna. Use of Metamaterial as substrate and circular split ring resonator leads to improve in antenna gain and size also reduced. The antenna was simulated, prototyped, and tested for plotting various performance measurements. The measured return loss is near to $-38 \mathrm{~dB}$ which results good impedance matching. The CSRRs loaded antenna achieves a measured peak realized gain of $6.2 \mathrm{dBi}$. Also some of the antenna characteristics improved than those presented in [14-17] listed in table 2. This paper is organized as below sections: In Sec. 2 Antenna Configuration, In Sec. 3 results and discussion and Sec. 4 presents conclusion of the work.

Table 1. Values of $x_{\mathrm{nm}}$ for different propagation modes

\begin{tabular}{cccccc}
\hline Modes(n,m) & 0,1 & 1,1 & 2,1 & 0,2 & 3,1 \\
\hline $\boldsymbol{x}_{\mathbf{n m}}$ & 0 & 1.84 & 3.05 & 3.83 & 4.20 \\
\hline
\end{tabular}

\section{Antenna configuration}

Initially, a conventional CPMA operating in $\mathrm{TM}_{02}$ mode is designed using the following expressions:

$$
\begin{gathered}
f_{n m}=\frac{X_{n m} C}{2 \pi a_{e} \sqrt{\epsilon_{r}}} \\
a_{e}=a\left[1+\frac{2 h}{\pi a \epsilon r}\left\{\ln \frac{\pi a}{2 h}+1.7726\right\}\right]^{1 / 2}
\end{gathered}
$$

Where, $f_{\mathrm{nm}}$ is the operating frequency, $X_{n m}$ is a constant (values for respective modes are presented in Table-1), $a_{e}$ is the effective radius of the patch, $a$ is the actual radius of the patch, $h$ is the thickness of the substrate and $\varepsilon_{\mathrm{r}}$ is the dielectric constant of the substrate. The calculated radius of the circular patch is $23.9 \mathrm{~mm}$.

The configuration of the proposed antenna is shown in Fig. 1. The proposed antenna is fabricated on a thin $(0.254 \mathrm{~mm}) \mathrm{RT} /$ Duroid 5880 Substrate for $50 \Omega$ input impedance and fed through probe feed [21] SMA Connector.

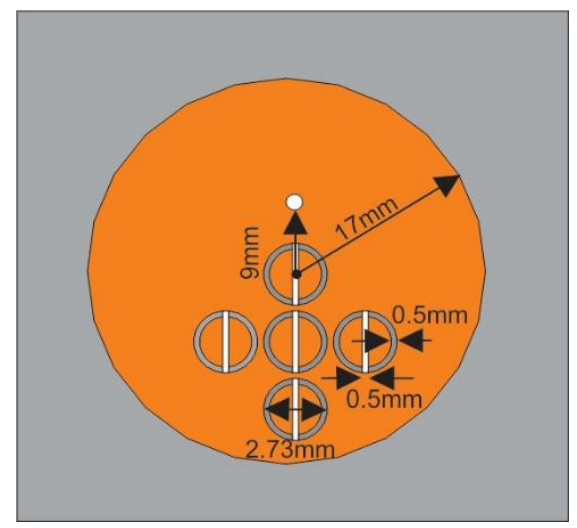

(a)

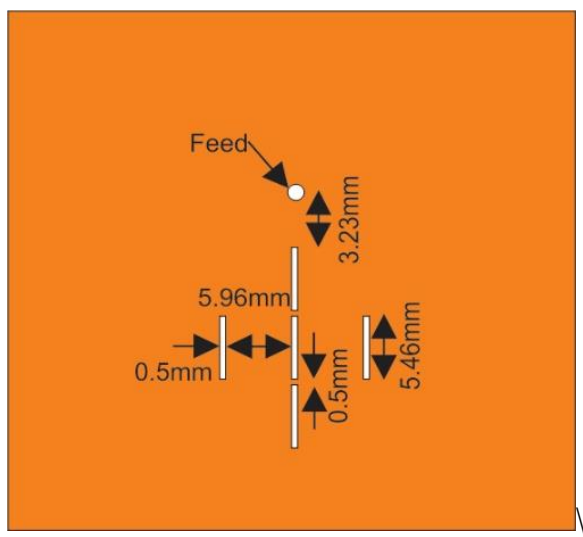

(b)

Figure. 1 Configuration of the proposed antenna: (a) top view and (b) bottom view 
Five CSRRs are loaded in the patch at optimized locations to alter the current distributions on the radiator (shown in Fig. 2). It can be seen in Fig. 2 that for the CSRRs loaded structure the surface current is focused on specific locations (left and right side of CSRRs) resulting in enhanced antenna gain.

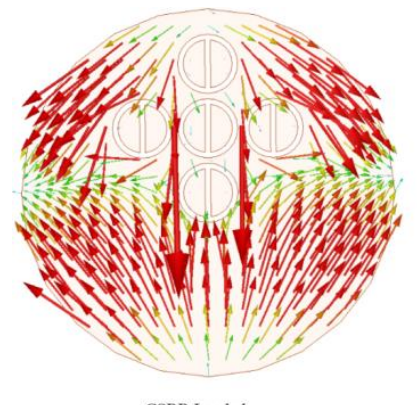

CSRR Loaded

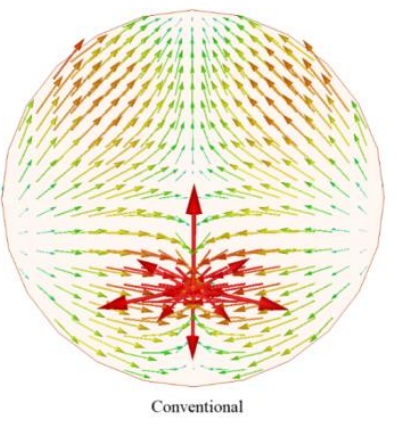

Convention
Figure. 2 Surface current distribution on the patch

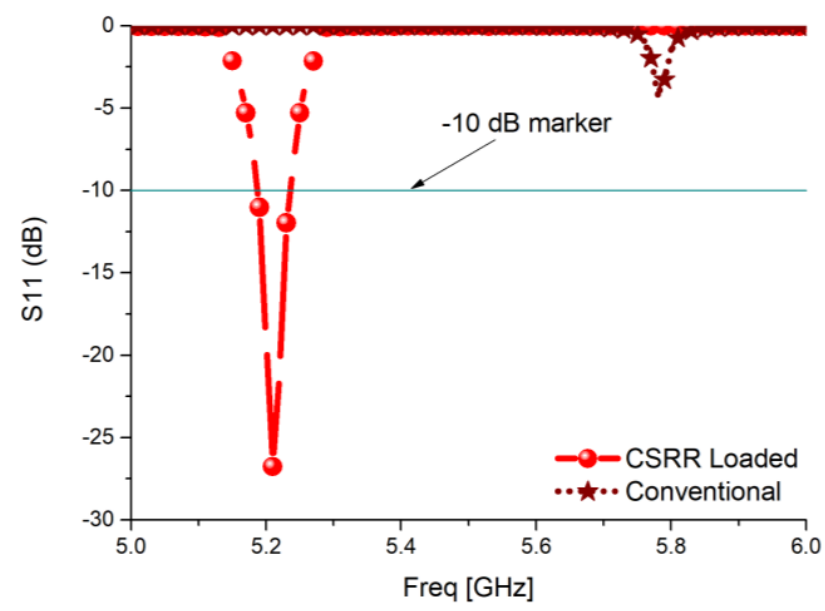

Figure. 3 Simulated S11 of the conventional and CSRR loaded antennas

It is observed in Fig. 3 that loading the CSRRs into the patch is shifting the operating frequency towards the lower side with improved impedance matching. Thus a smaller patch size is required to operate the antenna at $5.2 \mathrm{GHz}$ leading to significant miniaturization. On the contrary, loading the CSRRs are resulting in overall negative effective dielectric constant which improves the radiation performance of the structure.

The effective dielectric constant of the CSRRs loaded structure is extracted using scattering parameter inversion method, as shown in Fig. 4. The CSRRs loaded antenna is placed into an air-box and master-slave boundary conditions are applied to extract the transmission magnitude and phase characteristics.

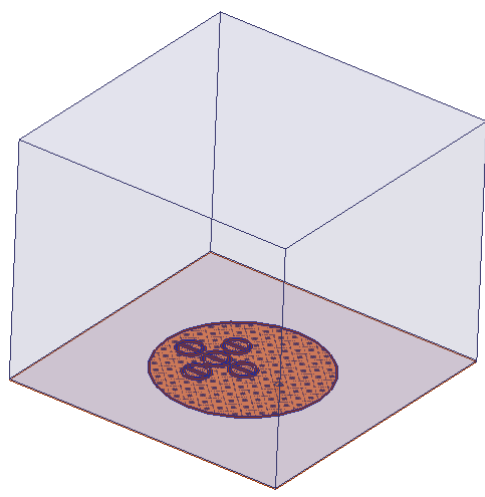

(a)

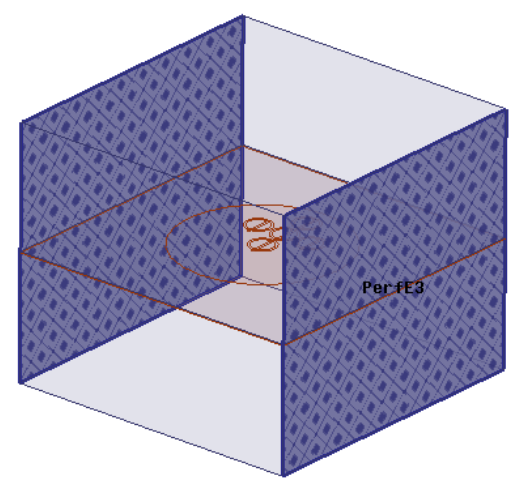

(b)

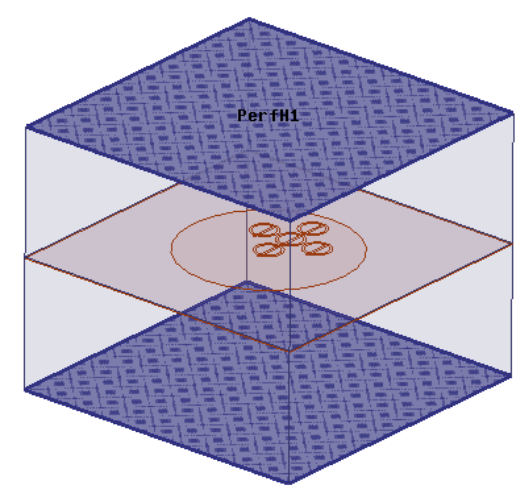

(c)

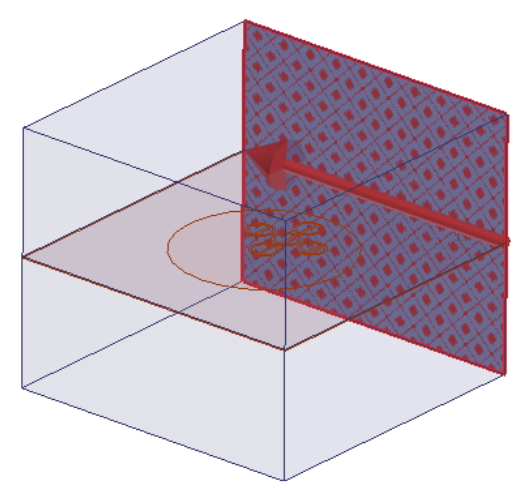

(d) 


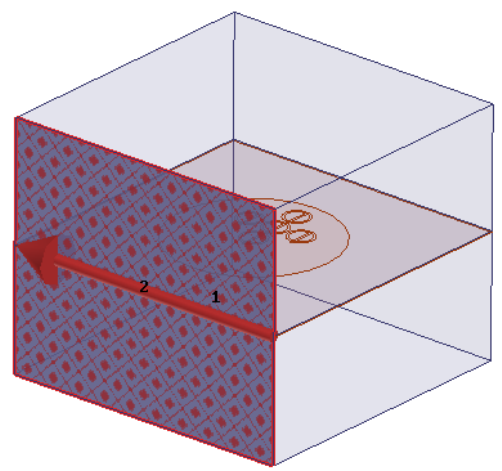

(e)

Figure. 4 Boundaries and excitation for scattering parameter inversion method: (a) antenna into the air box, (b) perfect E-field to a pair of horizontal faces, (c) perfect $\mathrm{H}$-field to the pair of horizontal faces, (d) master-slave 1, and (e) master-slave 2

Thereafter, dielectric constant of the overall structure is extracted using following MATLAB program:

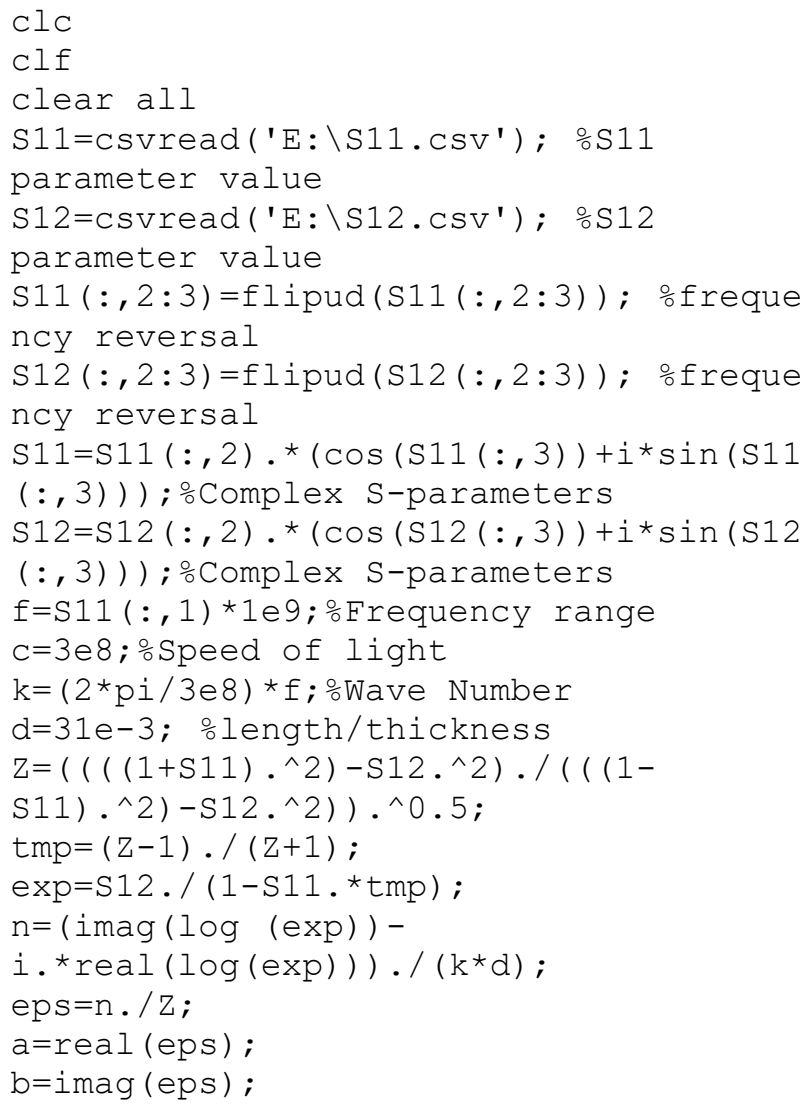

The process for extracting dielectric constant for overall structure is given below [22-23]:

To measures wave amplitudes and phases between ports in a network, yielding a matrix such as the one given below which relates incoming and outgoing waves [24].

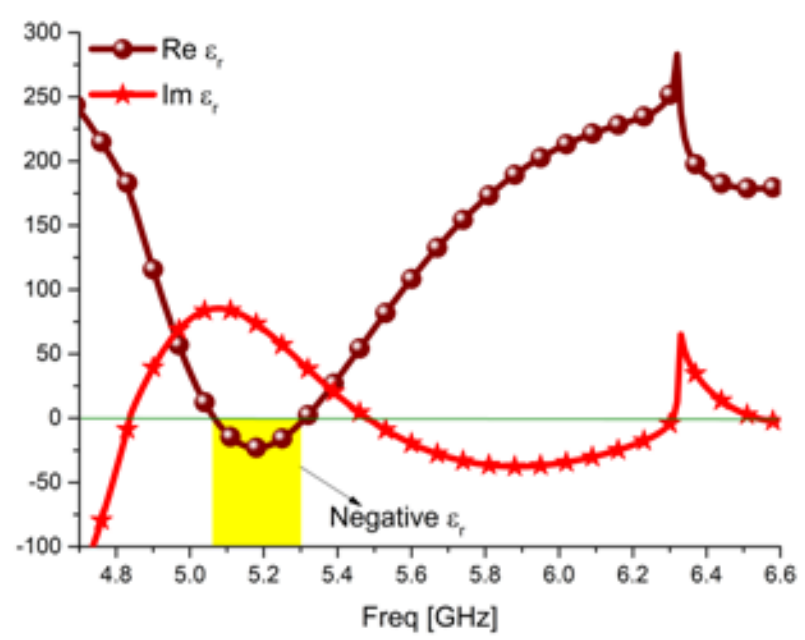

Figure. 5 Dielectric constant of CSRR loaded antenna structure

$$
\begin{aligned}
& S=\left[\begin{array}{ll}
S_{11} & S_{12} \\
S_{21} & S_{22}
\end{array}\right] \\
& \Gamma=\frac{Z-1}{Z+1}
\end{aligned}
$$

$\Gamma=$ relative material impedance

The approach considered here will determine $\mathrm{Z}$ and $\mathrm{n}$ then use these intermediate results to calculate permeability and permittivity.

$$
\begin{aligned}
& Z= \pm \sqrt{\frac{\left(1+S_{I 1}\right)^{2}-S^{2}{ }_{l 2}}{\left(1-S_{11}\right)^{2}-S^{2}{ }_{12}}} \\
& n=-\frac{1}{k_{0} d} \ln \left(\frac{S_{12}}{1-s_{11} \frac{Z-1}{Z+1}}\right)
\end{aligned}
$$

Here,

$\mathrm{n}=$ refractive index

$\mathrm{d}=$ length/thickness

$\mathrm{Z}=$ Impedance

$\mathrm{k}_{0}=$ Wave Number in vacume

If the material is passive, it must have a real part of $\mathrm{Z}$ that is positive.

Measurement of $\mathrm{S}$ parameters done using vector network analyzer.

The extracted dielectric constant of the CSRRs loaded antenna structure is shown in Fig. 5. It is evident that for $5.2 \mathrm{GHz}$ band, the antenna structure exhibits negative dielectric constant resulting in improved radiation performances. 


\section{Results and discussion}

The prototype of the antenna and S11 measurement setup is shown in Fig. 6. The S11 and gain of the antenna are measured using Vector Network Analyzer (VNA).

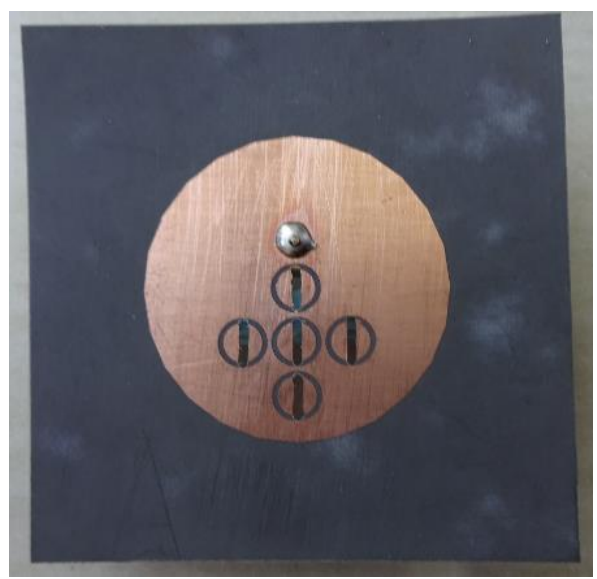

(a)

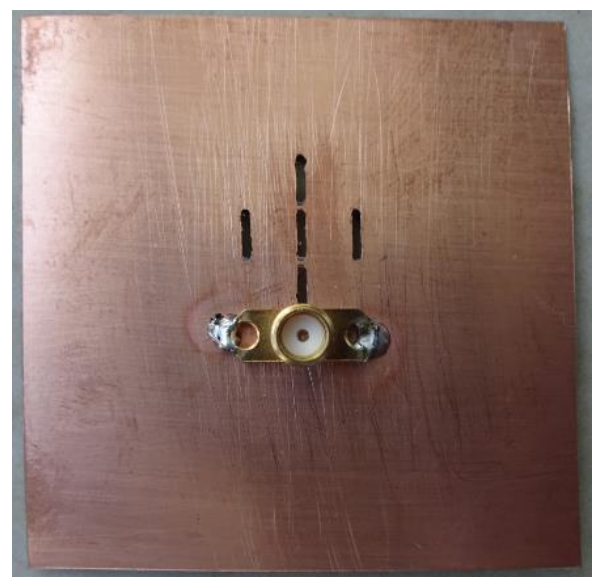

(b)

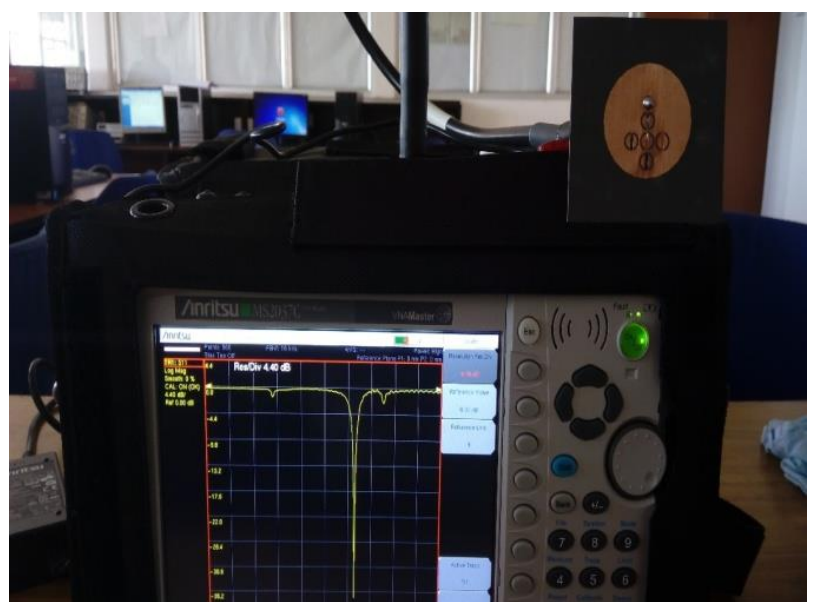

(c)

Figure. 6 Prototype and measurement setup: (a) top view of the prototype, (b) bottom view of the prototype, and (c) S11 measurement setup

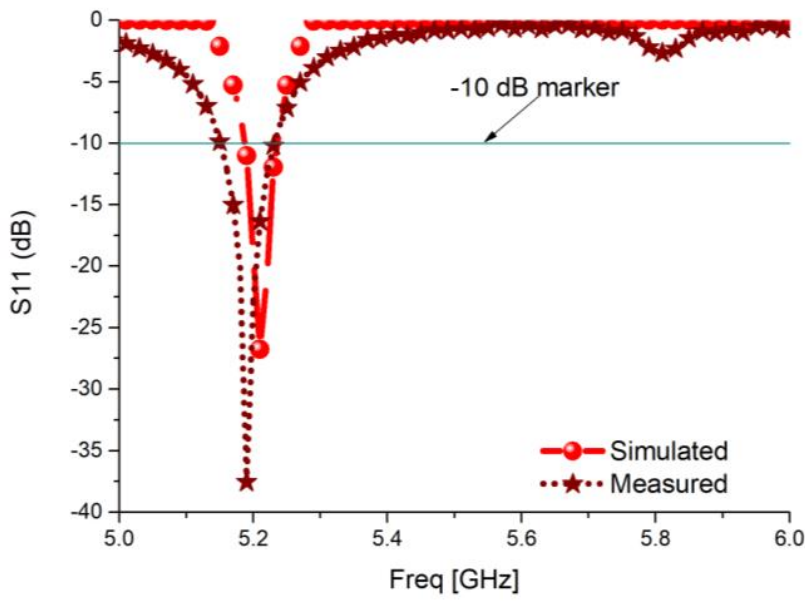

Figure. 7 Simulated and measured S11 parameter

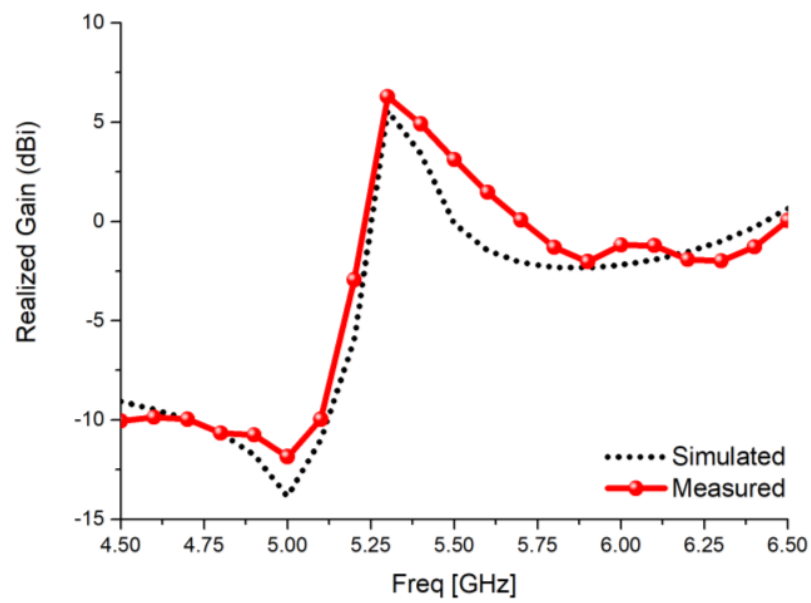

Figure. 8 Simulated and measured realized gain

The simulated and measured S11 parameter is shown in Fig. 7. The measured S11 has wider bandwidth and better impedance matching as evident in Fig. 7.

The simulated and measured frequency versus realized gain curve and simulated gain 3D-polar plot of the antenna at $5.2 \mathrm{GHz}$ is shown in Figs. 8 and 9 respectively.

The CSRRs loaded antenna achieves a measured peak realized gain of $6.2 \mathrm{dBi}$. It is evident in Fig. 9 that the loading the CSRRs improves the antenna gain by $4.58 \mathrm{dBi}$.

The simulated and measured $\mathrm{E}$ and $\mathrm{H}$-plane pattern of the antenna has very good accord, as shown in Fig. 10. Although the antenna has excellent gain and bi-conical radiation pattern, the antenna has quiet higher back radiations. 

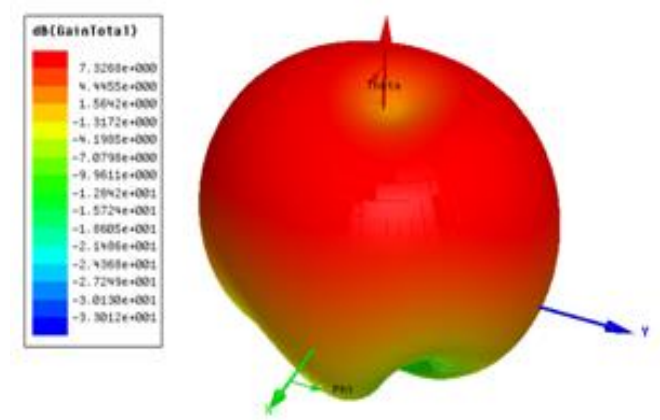

CSRR Loaded
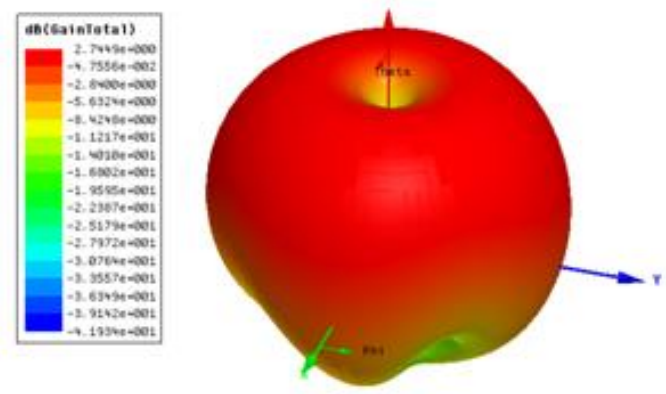

Conventional

Figure. 9 Simulated gain 3D-polar plot of CSRRs loaded and conventional antenna

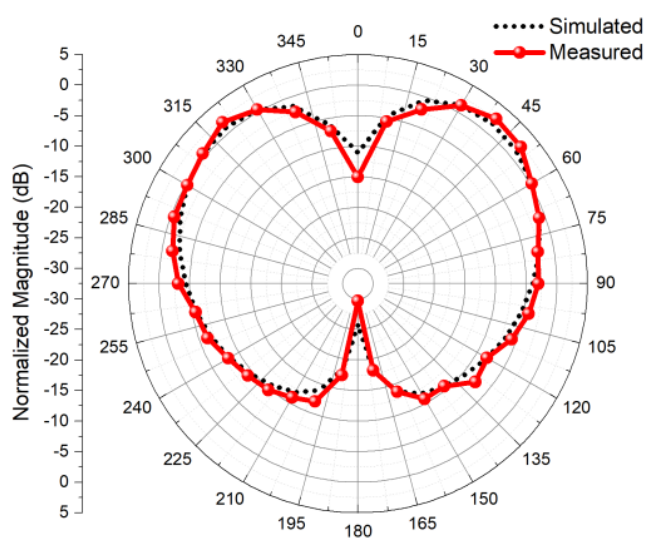

(a)

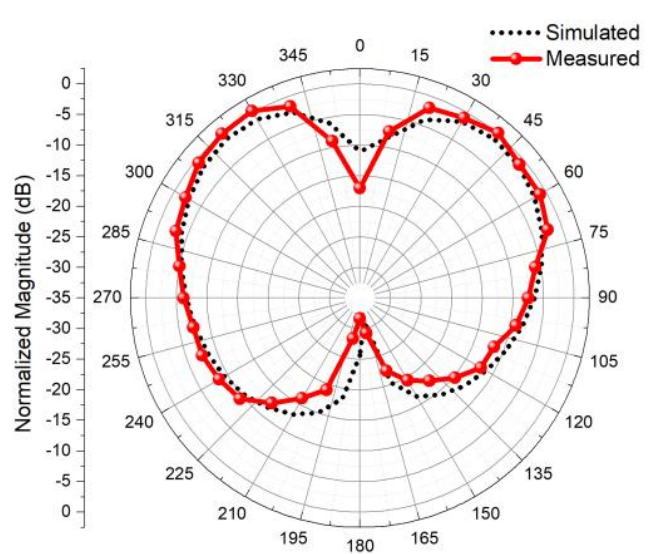

(b)

Figure. 10 Simulated and measured radiation pattern: (a) E-plane and (b) H-plane
Small differences between the simulated and measured results are observed which is due to the differences between the simulation model of materials and actual materials as a dielectric, connectors and metals.

Due to less thickness $(0.254 \mathrm{~mm})$ of the antenna it can be used as conformal antenna in future and the overall antenna footprint reduces that leads to size reduction of the antenna compare to the conventional antennas so it can be easily fit in to the anyplace. The use of split ring resonator enables rings to resonate at frequencies higher than closed rings. The structure of the resonator is simple. It has a split in its rings. The discontinuity in the ring produce capacitive effect and that increase the magnetic property of the object and good amount of radiation can be achieved. The gain achieved here is $6.2 \mathrm{dBi}$ due to use of metamaterial and the five circular split ring resonator, which is far better compare to the conventional designs. The return loss S11 curve realized below $-10 \mathrm{~dB}$ and the value is $38 \mathrm{~dB}$ which indicates good impedance matching and maximum power transfer takes place towards the antenna radiation side. Butterfly structure radiation pattern achieved which provides good coverage area of the device. Excellent agreement obtained between the experimental measurements and the numerical results.

\section{Conclusion}

A miniature circular patch antenna with improved realized gain and the bi-conical pattern is presented. The CSRRs loaded antenna is characterized by Scattering Parameter Inversion Method which is an effective method to extract material properties. Loading the CSRRs array into the patch modifies the overall dielectric properties of the structure thus, significantly affecting the antenna performances. By placing the optimized CSRR array into the antenna structure the performance of the antenna can be improved. The bi-conical pattern of the antenna is obtained by exciting the higher order mode. The return loss achieved is $-38 \mathrm{~dB}$ at $5.2 \mathrm{GHz}(1.2 \%$ bandwidth). The performance is better than that required to meet the demanding bandwidth specifications useful to cover the $5.2 \mathrm{GHz}$ frequency band which comes under wireless $\mathrm{C}$ band and various applications like wireless local area network (WLAN), high speed multimedia sharing etc. At the same time, using of five circular split ring resonators improves the performance of the proposed antenna and the antenna offers high gain of about $6.2 \mathrm{dBi}$. All these 
Table 2. Performance comparison of the proposed design and existing design

\begin{tabular}{|c|c|c|c|c|c|c|c|}
\hline Ref. No. & Year & $\mathbf{f}_{0}(\mathbf{G H z})$ & $\begin{array}{l}\text { Antenna } \\
\text { footprint }\end{array}$ & $\begin{array}{l}\text { Gain } \\
\text { (dBi) }\end{array}$ & $\begin{array}{c}\text { Minimum S11 } \\
\text { parameter }(\mathrm{dB})\end{array}$ & BW (\%) & Configuration \\
\hline 14 & 2017 & $1.9,2.5$ & $0.062 \lambda^{2}$ & $\begin{array}{l}4.52 \\
4.15\end{array}$ & -17 & $5.8,4$ & $\begin{array}{c}\text { External } \\
\text { Metasurface }\end{array}$ \\
\hline 15 & 2017 & 25 & $234.5 \lambda^{2}$ & 10.2 & -12 & 6 & $\begin{array}{c}\text { Integrated } \\
\text { Metasurface }\end{array}$ \\
\hline 16 & 2016 & 5.2 & $0.07 \lambda$ & 5.8 & -25 & 33.7 & $\begin{array}{c}\text { External } \\
\text { Metasurface }\end{array}$ \\
\hline 17 & 2016 & 4.45 & $1 \lambda^{2}$ & 10.2 & -23 & 8 & $\begin{array}{c}\text { External } \\
\text { Metasurface }\end{array}$ \\
\hline $\begin{array}{l}\text { Proposed } \\
\text { work }\end{array}$ & 2018 & 5.2 & $0.6 \lambda^{2}$ & 6.2 & -38 & 1.2 & Integrated \\
\hline
\end{tabular}

features are very useful for worldwide portability of wireless communication equipment and high speed services. Excellent agreement achieved between the experimental measurements and the numerical results.

In future a metasurface can be deployed beneath the antenna to suppress the back radiations also conformal antenna structure can be design and performance can be evaluated for various application, which can be mount on bent geometry or curved surface. Conformal types antenna provides wide coverage angle, Installation of radome not required so; eliminate the losses caused by radome, Improvement of aerodynamic profile etc.

\section{References}

[1] G. Kumar and K. P. Ray, Broadband Microstrip antennas, Artech House, Boston, 2003.

[2] V. G. Veselago, "The electrodynamics of substances with simultaneously negative values of $\varepsilon$ and $\mu$ ", Soviet Physics Uspekhi, Vol. 10, No. 4, pp. 509-514, 1968.

[3] D. R. Smith, W. J. Padilla, D. C. Vier, S. C. Nemat Nasser, and S. Schultz, "Composite Medium with Simultaneously Negative Permeability and Permittivity", Phys. Rev. Lett. 84, pp. 4184-4187, 2000.

[4] H. Ibach and H. Luth, "Solid-State Physics: An Introduction to Principles of Materials Science", Springer, 2009.

[5] S. K. Patel and Y. Kosta, "Triband Microstrip based radiating structure design using split ring resonator and complementary split ring resonator", Microwave Opt. Technol. Letter, Vol. 55, pp. 2219-2222, 2013.

[6] Y. Lee and Y. Hao, "Characterization of microstrip patch antennas on metamaterial substrates loaded with complementary split- ring resonators", Microwave Opt. Technol. Letter, Vol. 50, No. 8, pp. 2131-2135, 2008.

[7] S. K. Patel and Y. P. Kosta, "Dual band parasitic metamaterial square microstrip patch antenna design", International Journal of Ultra Wideband Communications and Systems Vol. 2, No. 4, pp. 225-232, 2012.

[8] K. M. Gupta and N. Gupta, "Advanced Semiconducting Materials and Devices", Springer, 2016.

[9] R. W. Ziolkowski and A. Kipple, "Application of double negative metamaterial to increase the power radiated by electrically small antennas", IEEE Trans on Antennas and Propagation, Vol. 51, No. 10, pp. 2626-2640, 2013.

[10] K. Fujimoto and H. Morishita, "Modern Small Antennas", Cambridge University Press, 2014.

[11] Suntives and R. Abhari, "Miniaturization and isolation improvement of a multiple-patch antenna system using electromagnetic band gap structures", Microwave and Optical Technology Letters, Vol. 55, No. 7, pp. 1609-1612, 2013.

[12] Y. J. Park, A. Herschlein, and W. Wiesbeck, "A photonic band gap (PBG) structure for guiding and suppressing surface waves in millimetre wave antennas", IEEE Transactions on Microwave Theory and Techniques, Vol. 49, No. 10, pp. 1854-1859, 2001.

[13] J. Colburn and Y. R. Samii, "Patch antennas on externally perforated high dielectric constant substrates", IEEE Transactions on Antennas and Propagation, Vol. 47, No. 12, pp. 17851794, 1999.

[14] T. Yue, Z. H. Jiang, A. H. Panaretos, and D. H. Werner, "A Compact Dual-Band Antenna Enabled by a Complementary Split-Ring Resonator Loaded Metasurface", IEEE Transactions on Antennas and Propagation, Vol. 65, No. 12, pp. 6878-6888, 2017. 
[15] O. Yurduseven and D. R. Smith, "DualPolarization Printed Holographic Multi beam Metasurface Antenna", IEEE Antennas and Wireless Propagation Letters, Vol. 16, pp. 2738-2741, 2017.

[16] W. Zhao, L. Long, L. Yongjiu, and C. Xi, "Metasurface superstrate antenna with wideband circular polarization for satellite communication application", IEEE Antennas and Wireless Propagation Letters, Vol. 15, pp. 374-377, 2016.

[17] Z. Hailiang, C. W. Sing, and Y. I. Tung, "Enhancing Antenna Boresight Gain Using a Small Metasurface Lens Reduction in half power beamwidth", IEEE Antennas \& Propagation Magazine, pp. 35-44, 2016.

[18] S. Gupta and R. L. Sharma, "Design, performance analysis and comparison of nearly square, nearly square corner trimmed and nearly square corner trimmed with slot antenna for 5.2 GHZ wireless applications", VSRD International Journal of Technical \& Non Technical Research, Vol. 8, No. 8, pp. 209-214, 2017.

[19] M. Sarkar, S. Banerjee, Y. Badr, and A. K. Sangaiah, "Configuring a Trusted Cloud Service Model for Smart City Exploration using Hybrid Intelligence”, International Journal of Ambient Computing and Intelligence, Vol. 8, No. 3, pp.1-21, 2017.

[20] A. Ahmad, "Wireless and Mobile Data Networks", Wily, 2015.

[21] S. Gupta and R. L. Sharma, "Microstrip patch antenna and applications", VSRD International Journal of Technical \& Non-Technical Research, Vol. 7, pp. 171-174, 2016.

[22] A. M. Nicolson and G. F. Ross, "Measurement of the intrinsic properties of materials by timedomain techniques", IEEE Transactions on Instrumentation and Measurement, Vol. IM-19, No. 4, pp. 377-382, 1970.

[23] W. B. Weir, "Automatic measurement of complex dielectric constant and permeability at microwave frequencies", Proceedings of the IEEE, Vol. 62, No. 1, pp. 33-36, 1974.

[24] D. Pozar, Microwave Engineering, 3rd ed, John Wiley, 2004. 